\title{
Fracture Toughness Prediction for MWCNT Reinforced Ceramics
}

$\mathrm{CH}$ Henager, Jr.

BN Nguyen

September 2013

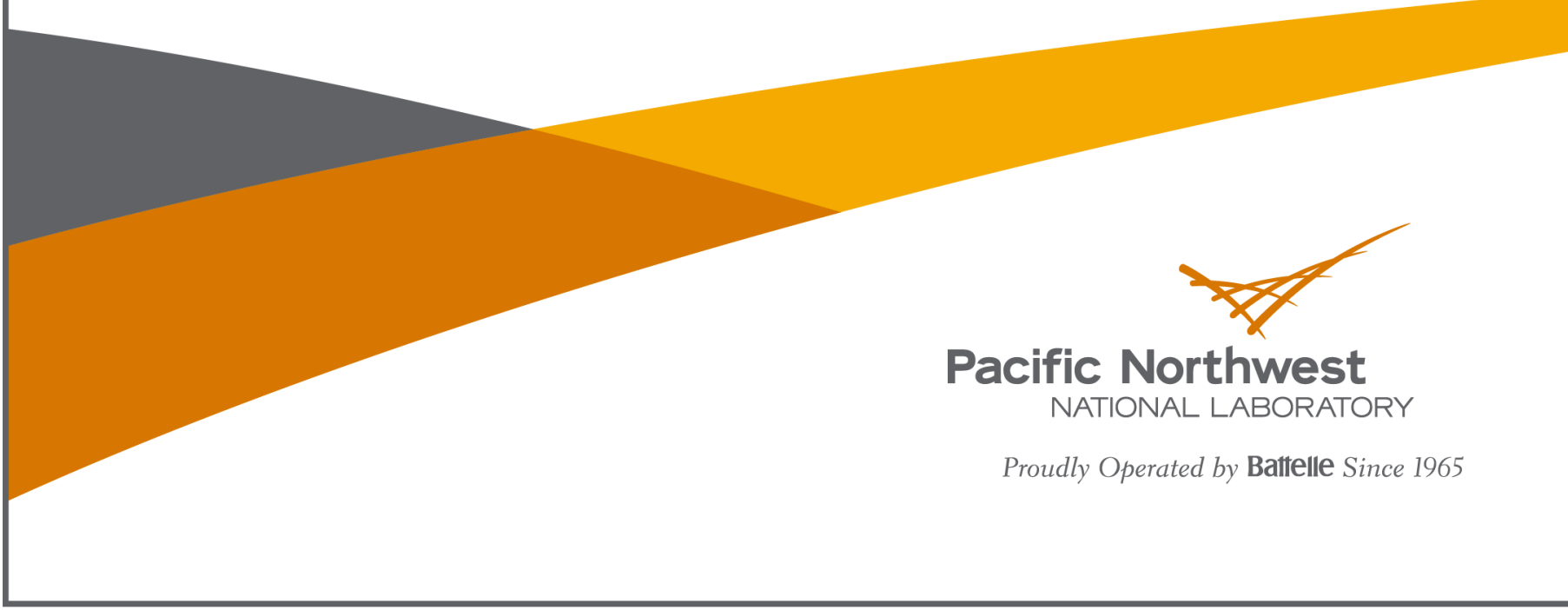




\title{
DISCLAIMER
}

This report was prepared as an account of work sponsored by an agency of the United States Government. Neither the United States Government nor any agency thereof, nor Battelle Memorial Institute, nor any of their employees, makes any warranty, express or implied, or assumes any legal liability or responsibility for the accuracy, completeness, or usefulness of any information, apparatus, product, or process disclosed, or represents that its use would not inf ringe privately owned rights. Reference herein to any specific commercial product, process, or service by trade name, trademark, manufacturer, or otherwise does not necessarily constitute or imply its endorsement, recommendation, or favoring by the United States Government or any agency thereof, or Battelle Memorial Institute. The views and opinions of authors expressed herein do not necessarily state or reflect those of the United States Government or any agency thereof.

\author{
PACIFIC NORTHWEST NATIONAL LABORATORY \\ operated by \\ BATTELLE \\ for the \\ UNITED STATES DEPARTMENT OF ENERGY \\ under Contract DE-AC05-76RL01830
}

Printed in the United States of America
Available to DOE and DOE contractors from the
Office of Scientific and Technical Information,
P.O. Box 62, Oak Ridge, TN 37831-0062;
ph: (865) 576-8401
fax: $(865) 576-5728$
email: reports $(\boldsymbol{a})$ donis.osti.gov

Available to the public from the National Technical Information Service

5301 Shawnee Rd., Alexandria, VA 22312

ph: (800) 553-NTIS (6847)

email: orders@ntis.gov $<$ http://www.ntis.gov/about/form.aspx $>$

Online ordering: http://www.ntis.gov

This document was printed on recycled paper. 


\section{Fracture Toughness Prediction for MWCNT Reinforced Ceramics}

$\mathrm{CH}$ Henager, Jr.

BN Nguyen

September 2013

Prepared for

the U.S. Department of Energy

under Contract DE-AC05-76RL01830

Pacific Northwest National Laboratory

Richland, Washington 99352 



\section{Summary}

This report describes the development of a micromechanics model to predict fracture toughness of multiwall carbon nanotube (MWCNT) reinforced ceramic composites to guide future experimental work for this project. The modeling work described in this report includes (i) prediction of elastic properties, (ii) development of a mechanistic damage model accounting for matrix cracking to predict the composite nonlinear stress/strain response to tensile loading to failure, and (iii) application of this damage model in a modified boundary layer (MBL) analysis using ABAQUS to predict fracture toughness and crack resistance behavior (R-curves) for ceramic materials containing MWCNTs at various volume fractions.

The modeling work provides insight and guidance to processing these materials for optimized composite microstructures to achieve the mechanical properties needed for high-temperature structural applications. The predictions show that homogeneously dispersed MWCNTs in a ceramic matrix significantly increase the resulting composite stiffness, strength, and fracture toughness. However, the fracture toughness increases may not attain the levels needed for the applications of these materials in advanced nuclear reactors. In addition, even assumingly well-distributed MWCNTs, the tensile strength and fracture toughness values saturate at moderate MWCNT volume fractions and tend to decrease at relatively high MWCNT volume fractions. Actually, the experimental difficulties to homogenously disperse MWCNTs throughout the matrix limit the MWCNT contents that can be achieved by mixing nanocrystalline $\mathrm{SiC}$ powders with MWCNTs and suggest that other processing methods and microstructural solutions need to be sought to better explore the load-carrying capacity of MWCNTs. In this report, predictions of fracture toughness as a function of MWCNT volume fraction have been validated against the experimental data for a MWCNT nanostructured zirconia composite determined by Mazaheri et al. (2011). The results of this report are valuable guidance to the experimental portion of this project and suggest that the development of additional toughening mechanisms needs to be explored in order to achieve the project goals of adequate fracture toughness for nuclear reactor structural applications. 



\section{Acronyms and Abbreviations}

$\begin{array}{ll}3 \text { YSZ } & 3 \text { mol\% yttria stabilized zirconia } \\ \text { CNT } & \text { carbon nanotube } \\ \text { EMTA } & \text { Eshelby-Mori-Tanaka Approach } \\ \text { FE } & \text { finite element } \\ \text { MBL } & \text { modified boundary layer } \\ \text { MWCNT } & \text { multiwall carbon nanotube } \\ \text { PNNL } & \text { Pacific Northwest National Laboratory } \\ \text { SEVNB } & \text { single edge V-notched beam } \\ \text { SW } & \text { single wall } \\ \text { UD } & \text { unidirectional } \\ \text { VE } & \text { vanishing element }\end{array}$





\section{Contents}

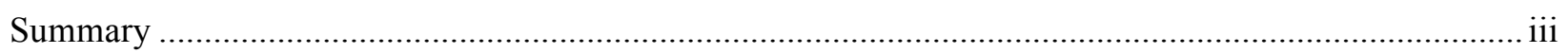

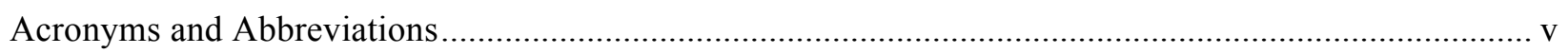

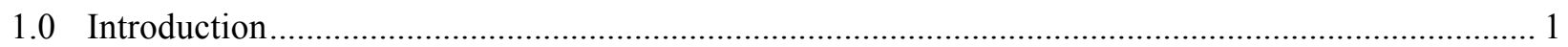

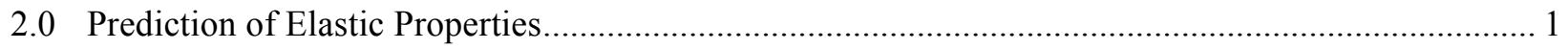

3.0 A Mechanistic Damage Model for MWCNT Ceramic Composites .................................................... 3

4.0 Prediction of Fracture Toughness for MWCNT Reinforced Ceramics ….......................................... 5

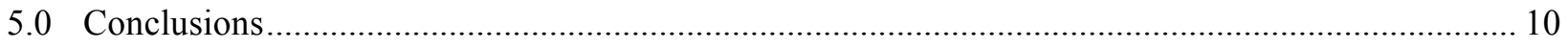

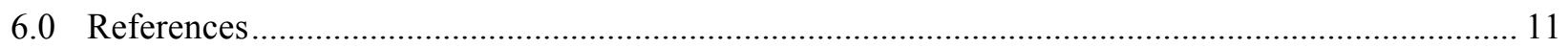




\section{Figures}

1 Schematic of the EMTA Homogenization Procedure .................................................................. 2

2 A Prediction of for the Equivalent CNT Elastic Moduli as a Function of the Number of

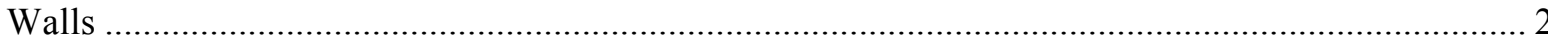

3 Measured and Predicted Shear Modulus for a MWCNT/3YSZ System as a Function of MWCNT Volume Fraction ....

4 Tensile Stress/Strain Response Predicted for MWCNT/3YSZ as a Function of the MWCNT

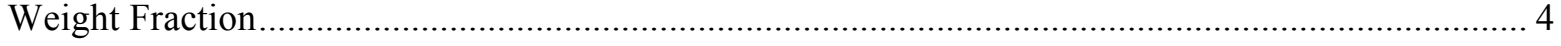

5 Principle of the MBL Modeling Approach …........................................................................... 5

6 (a) Finite Element (FE) Mesh for the MBL Analysis and (b) a Zoom of the FE Mesh for the Damage/Fracture Process Window

7 Predicted Damage Distribution at the Onset of Crack Propagation for the 3-wt $\%$ MWCNT/3YSZ

8 Predicted and Experimental Mode I Fracture Toughness vs. MWCNT Volume Fraction for

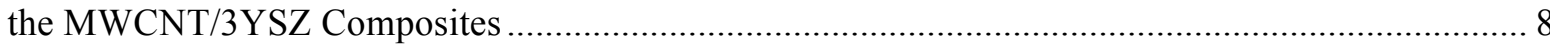

9 Predicted Crack Propagation for the $3-\mathrm{wt} \% \mathrm{MWCNT} / 3 \mathrm{YSZ}$ at $K_{\mathrm{I}}=K_{\mathrm{I}}^{\mathrm{R}}=9.47 \mathrm{MPa} \cdot \sqrt{\mathrm{m}} \ldots \ldots \ldots \ldots \ldots$

10 Predicted Stress Intensity Factor vs. Crack Advance for the MWCNT/3YSZ Composites as a Function of MWCNT Content 10

\section{Tables}

1 R-curves Power-Law Coefficients Identified for the MWCNT/3YSZ Composites Studied in this Report 10 


\subsection{Introduction}

Pacific Northwest National Laboratory (PNNL) is developing a new high-temperature structural material based on nanocrystalline $\mathrm{SiC}$ alloys that can be used in advanced reactors as an accident tolerant replacement for zircaloy cladding or as an improved SiC cladding for TRISO fuel, as well as for certain other in-core applications that require higher temperature use properties. Operation at $823 \mathrm{~K}$ to $1700 \mathrm{~K}$ is well within the range of these materials provided that they have the requisite fracture toughness. This research will focus on modification of mechanical properties of $\mathrm{SiC} / \mathrm{Ti}_{3} \mathrm{SiC}_{2}$ nanocomposites, with and without 3D-textured carbon nanotube reinforcements. Predictive modeling using a multiscale mechanistic approach will be performed to predict and tailor the basic mechanical properties of the asformed composites; that is, stiffness and stress-strain responses up to failure. The modeling task will provide guidance to assist in material design and processing for improved material ductility and strength. We propose to produce a series of $\mathrm{SiC} / \mathrm{Ti}_{3} \mathrm{SiC}_{2}$ nanocrystalline alloys with and without $3 \mathrm{D}$-textured carbon nanotube (CNT) reinforcements with sufficient toughness to be able to serve as high-temperature reactor structural materials and fuel-cladding materials with dramatically improved performance. Including 3D-textured CNT mats or dispersed CNTs appears to be required for additional toughening. To the best of our knowledge, this type of CNT tailoring has not yet been discussed or considered for SiCbased composites. Imprinting of high-density CNT mats will be used to prepare textured CNTreinforcements for improved mechanical and thermal properties compared to conventional SiC-based materials. The modeling reported here will be used to guide further research into toughening SiC alloys using CNTs and CNT mats. This report is limited to models of dispersed CNTs in SiC using data from the literature for CNT-toughened zirconia. The report demonstrates the limits of CNT toughening in ceramics that must be overcome with an approach that goes beyond dispersed CNTs; that is, textured CNT mats.

\subsection{Prediction of Elastic Properties}

Reinforcing a ceramic matrix with dispersed nanoparticles or carbon nanotubes (CNTs) at moderate volume fractions can achieve significant increases in elastic moduli for the resulting composite. These increases are higher than those obtained with the use of conventional fibers. The so-called nano-effect from the existence of an interphase between the nano-reinforcement phase and matrix material is responsible for the significant enhancement of the composite elastic moduli. In this work, a Pacific Northwest National Laboratory (PNNL) computer tool named EMTA (Eshelby-Mori-Tanaka Approach) for the computation of the composite thermoelastic properties (Nguyen 2010b) was modified to account for the nano-effect in multiwall carbon nanotube (MWCNT) composite. Figure 1 gives a schematic description of the EMTA computation procedure for MWCNT composites. The computation considers the unidirectional (UD) composite containing aligned single- or multiwall CNTs (Figure 1(a)) from which the first EMTA homogenization is performed to obtain the homogenized elastic stiffness of the CNT/interphase system (Figure 1(b)). Next, the second EMTA homogenization is carried out to determine the elastic stiffness of the UD composite containing aligned equivalent fibers and embedded in a matrix material (Figure 1(c)). Finally, the fiber orientation averaging technique (Advani and Tucker III 1987) is applied to compute the elastic stiffness of the as-formed composite having a fiber orientation distribution (Figure 1(d)). 


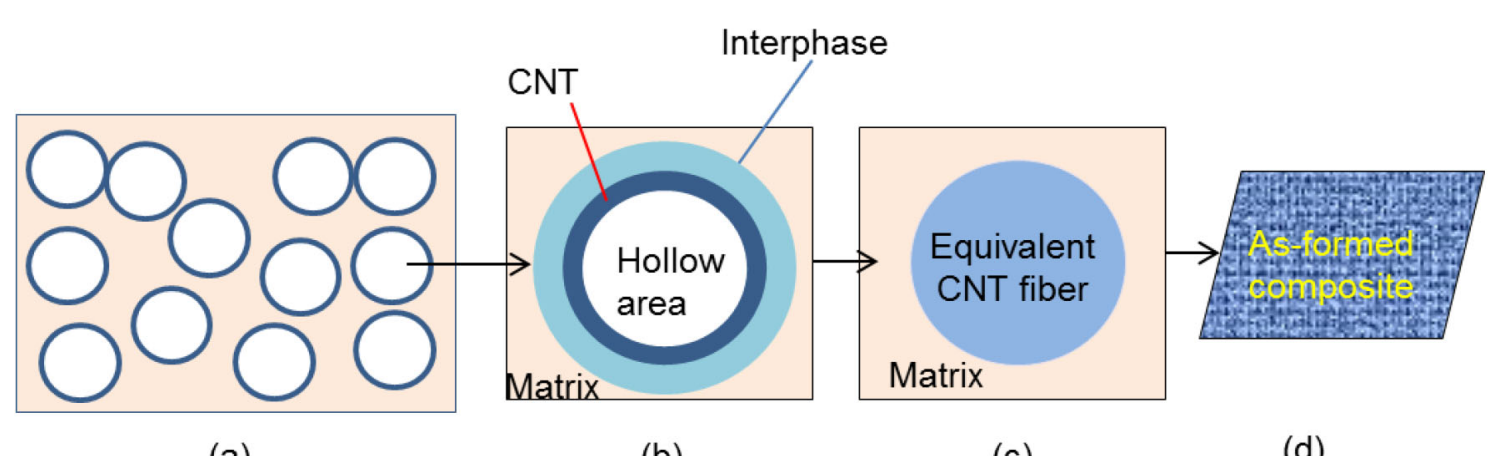

(a)

(b)

(c)

(d)

Figure 1. Schematic of the EMTA Homogenization Procedure

Using MWCNTs instead of single-wall (SW) CNTs reduces the hollow space inside the tubes and consequently increases the CNT elastic moduli importantly, and renders the tube behavior isotropic with the transverse elastic modulus approaching the longitudinal modulus (Figure 2) for a large number of walls. The elastic moduli of MWCNTs having a large number of walls asymptotically approaches the elastic modulus of graphene, which is approximately $915 \mathrm{GPa}$. Figure 2 reports the EMTA predictions for the equivalent (homogenized) CNT elastic moduli that attain the graphene elastic modulus for the number of walls equal to 35 .

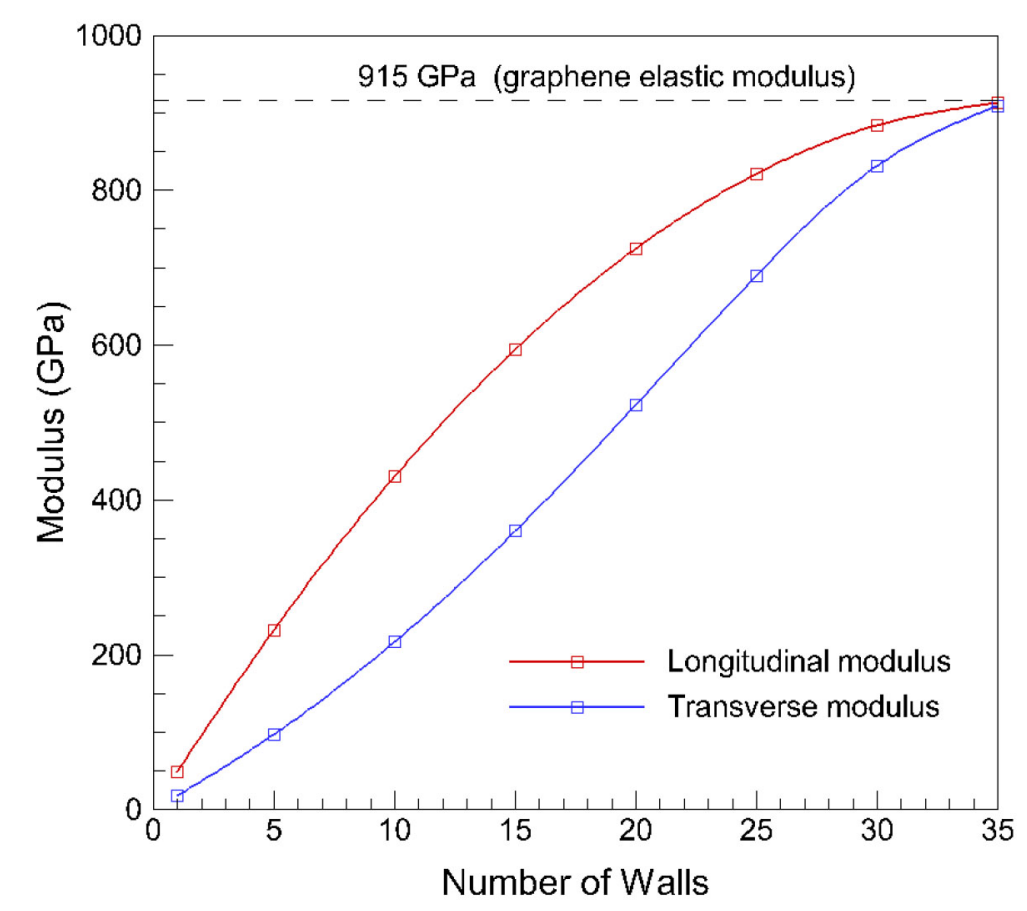

Figure 2. A Prediction of for the Equivalent (homogenized) CNT Elastic Moduli as a Function of the Number of Walls 
Figure 3 presents EMTA predictions compared to Mazaheri et al.'s measured data (Mazaheri et al. 2011) for the shear modulus of a MWCNT/3YSZ ( $3 \mathrm{~mol} \%$ yttria stabilized zirconia) system as a function of the MWCNT volume fraction. This composite system was processed by spark plasma sintering (Mazaheri et al. 2011). The results show that dispersing small MWCNT contents in 3 YSZ has significantly increased the shear modulus of the as-formed composite, and a good agreement between the predicted and measured moduli is obtained using the EMTA model with interphase (Figure 1). It is noted that the difficulty to homogeneously distribute higher MWCNT contents in the matrix has limited the increase in modulus, and that explains the deviation between the predicted and experimental results for higher MWCNT volume fractions.

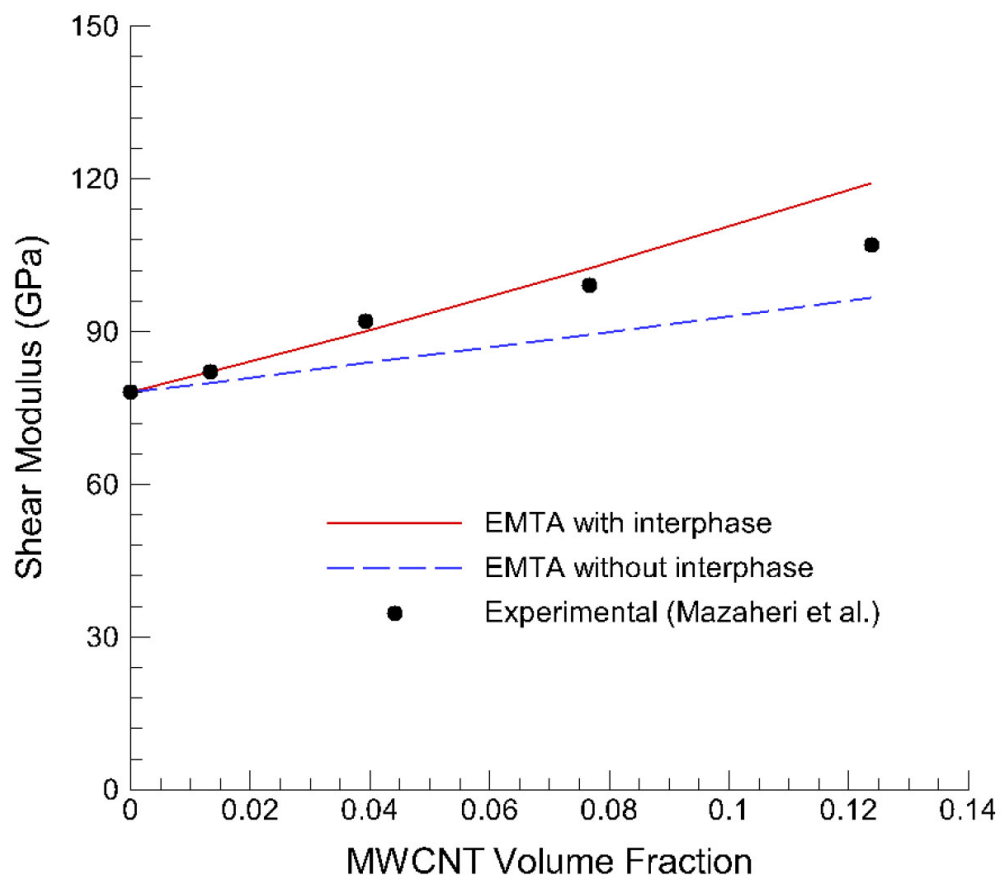

Figure 3. Measured and Predicted Shear Modulus for a MWCNT/3YSZ System as a Function of MWCNT Volume Fraction. The experimental results are from Mazaheri et al. (2011).

\subsection{A Mechanistic Damage Model for MWCNT Ceramic Composites}

To predict the composite fracture toughness, it is necessary to model the damage development that affects its stiffness in order to compute the composite stress/strain response to monotonic loading up to failure. MWCNT ceramic composites subjected to monotonic or cyclic loadings suffer from matrix cracking. Matrix cracking has been identified as the key mechanism responsible for damage and failure of discontinuously reinforced materials from fiber end stress concentrations. In MWCNT ceramics, the brittle ceramic matrix is more likely prone to cracking. 
We have developed a mechanistic damage model to describe matrix cracking in MWCNT ceramic composites. The model derived from a model for glass-ceramics developed by Nguyen et al. (2006) is termed "mechanistic" as its formulation uses both micromechanics and continuum damage mechanics. It assumes elastic MWCNTs completely randomly dispersed in a ceramic matrix whose cracking behavior is described by a continuum damage description. An incremental EMTA method combined with a fiber orientation averaging procedure is used to incrementally determine the composite response. The damage model has been implemented in EMTA-NLA, a PNNL's capability used with the ABAQUS finite element (FE) package for nonlinear structural analyses (Nguyen 2010a). The details of this damage model and its implementation are reported in our article in preparation. ${ }^{(\text {a) }}$

Figure 4 presents the stress/strain responses as a function of the MWCNT weight fraction predicted by the damage model for this composite system subjected to tensile loading to failure. The experimental stress/strain curves are not known. The predicted increase in tensile strength is substantial for the composite with 5-wt\% MWCNT (12.4\% volume fraction). As observed for the elastic moduli (Figure 3), it is expected that the actual strength (if available) would be lower than the predicted strength for this value of MWCNT content because of the difficulty to homogeneously distribute MWCNTs in the matrix.

\section{MWCNT/3YSZ}

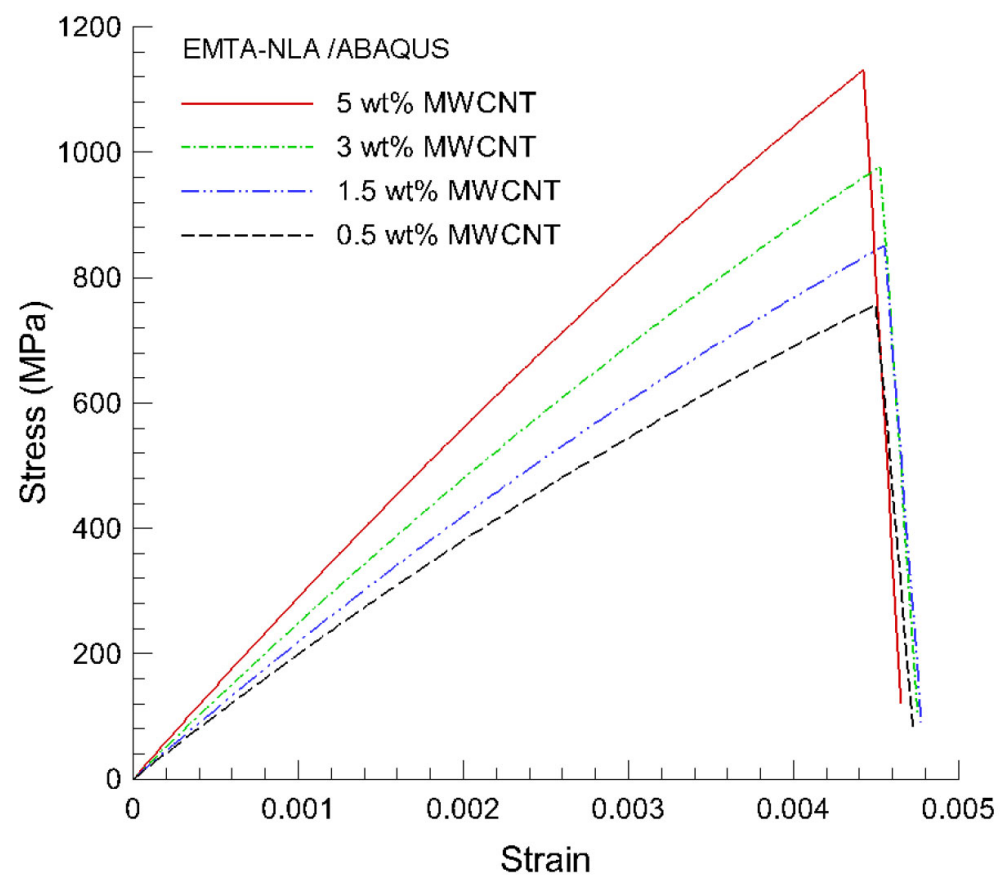

Figure 4. Tensile Stress/Strain Response Predicted for MWCNT/3YSZ as a Function of the MWCNT Weight Fraction

(a) Nguyen BN, et al. 2013. "Fracture Toughness Prediction for MWCNT Reinforced Ceramics Using a Modified Boundary Layer Modeling Approach. In preparation. 


\subsection{Prediction of Fracture Toughness for MWCNT Reinforced Ceramics}

The damage model developed for MWCNT reinforced ceramics was used in a modified boundary layer (MBL) modeling approach to predict the composite fracture toughness under Mode I loading. The MBL modeling approach was initially proposed by Tvergaard and Hutchinson (1992) to investigate crack growth resistance in elastic-plastic solids. Later, it was also used by other authors (Onck and Van der Giessen 1999; Nguyen et al. 2000) to study damage and fracture in a small process zone at a tip of an existing crack. The principle of the MBL modeling approach is described in Figure 5. Consider an initial crack inside a solid subjected to loading at the solid boundaries (Figure 5(a)). If one is interested in conditions for the onset of crack propagation and growth, and the governing parameters, an approach to damage and fracture at the microstructural scale is appropriate. One way to model damage and fracture process at this scale, and still keep track of the remote boundary conditions, is to use an MBL modeling approach (Figure 5(b)). This approach is defined as small-scale damage and fracture analysis. It relies on the assumption that damage and fracture is allowed only to develop in a process zone containing an initial crack tip. The process zone must be much smaller than all relevant specimen/structure dimensions so that a boundary layer problem can be formulated with the crack-tip fields in an undamaged solid as the remote boundary conditions applied on the outer contour of a circular region containing the process zone (Figure 5(b)). The MBL analysis can be efficiently used to characterize the material fracture toughness and crack resistance behavior without modeling the whole structure with the associated boundary conditions. These, however, are represented in an MBL model through the asymptotic crack-tip fields.

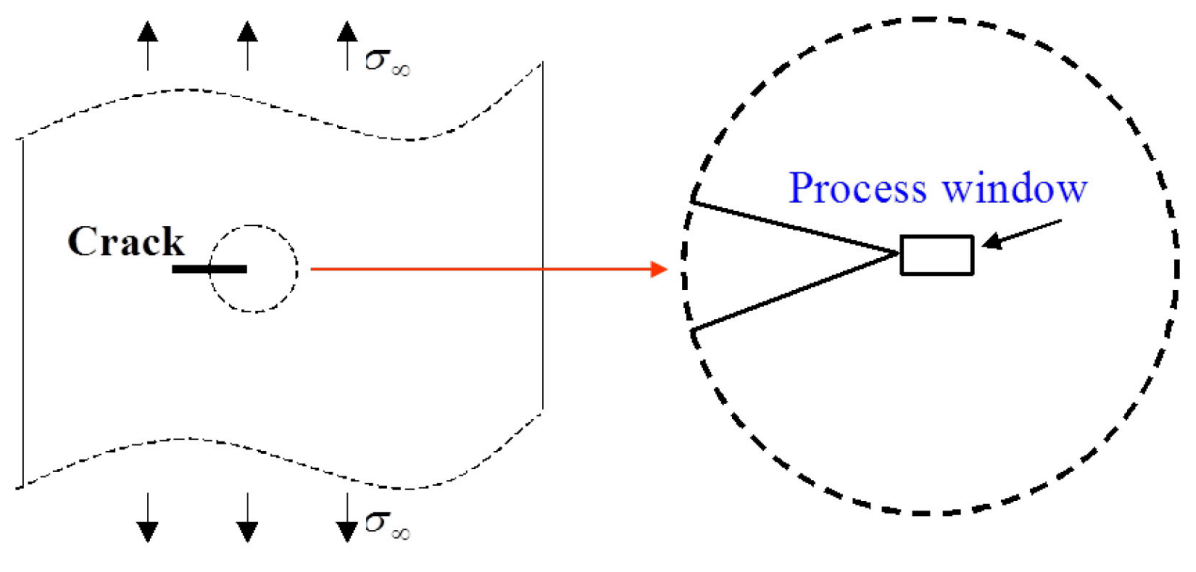

(a)

(b)

Figure 5. Principle of the MBL Modeling Approach: (a) a crack inside a body subjected to remote loading, and (b) a damage process window containing a crack-tip and surrounded by a circular region where the asymptotic crack-tip fields are prescribed as boundary conditions (Nguyen et al. 2006).

For the MWCNT ceramic composites studied in this report, the MWCNTs are assumed to be completely randomly distributed in the ceramic matrix; thus, the homogenized behavior is isotropic, and the crack-tip fields for a crack in an elastic isotropic solid are then used as the remote boundary conditions 
for the MBL analysis. Under plane-strain condition and Mode I loading, the crack-tip displacement components in an elastic solid are given by:

$$
\begin{aligned}
& u_{1}=\frac{K_{\mathrm{I}}}{2 \mu} \sqrt{\frac{r}{2 \pi}} \cos \left(\frac{\theta}{2}\right)\left[\kappa-1+2 \sin ^{2}\left(\frac{\theta}{2}\right)\right], \\
& u_{2}=\frac{K_{\mathrm{I}}}{2 \mu} \sqrt{\frac{r}{2 \pi}} \sin \left(\frac{\theta}{2}\right)\left[\kappa+1-2 \cos ^{2}\left(\frac{\theta}{2}\right)\right]
\end{aligned}
$$

where $r$ and $\theta$ are the polar coordinates centered at the crack tip. $K_{\mathrm{I}}$ denotes the Mode I loading stress intensity factor, $\mu$ is the shear modulus, and $\kappa$ is given by $\kappa=3-4 v$ with $v$ being the Poisson ratio.

The damage model developed for MWCNT ceramic composites discussed in the previous section was used to describe the development of damage leading to crack growth in the process zone. The composite behavior away from the process zone remains linear elastic. Under increasing loading applied via boundary conditions (Eq. 1), damage evolves at the crack tip until attaining a critical stage characterized by the critical value of the damage variable. The critical damage stage represents the onset of crack propagation in the damage process window, and the corresponding value of $K_{\mathrm{I}}$ at this stage defines the material Mode I fracture toughness, $K_{\mathrm{I}}^{\mathrm{c}}$. Crack propagation in the process window is captured by a vanishing element technique proposed by Nguyen et al. (2006).

Figure 6 presents the finite element mesh designed for the MBL analysis to predict fracture toughness of the MWCNT/3YSZ composite studied in this report. The whole mesh for the MBL problem is given in Figure 6(a) while Figure 6(b) shows the mesh in the process window. The outer diameter of the circular region must be much greater than the size of the process window so that damage and fracture occurring in the process window do not affect the remote fields. In this work, the dimension of the process window and the outer diameter of the circular region (Figure 6) are $0.7 \mathrm{~mm}$ and $70 \mathrm{~mm}$, respectively.

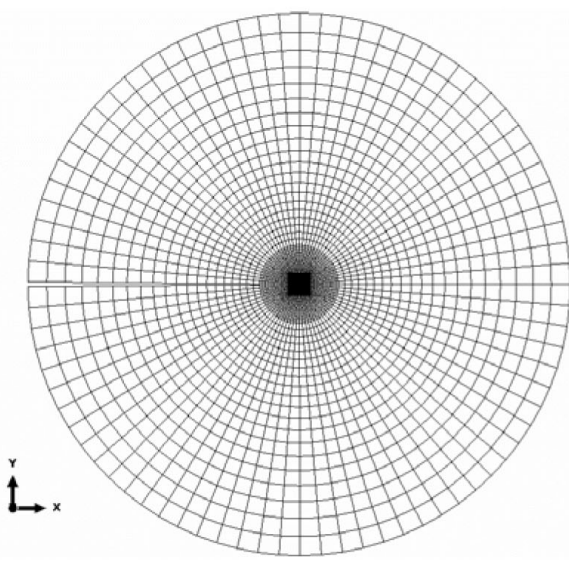

(a)

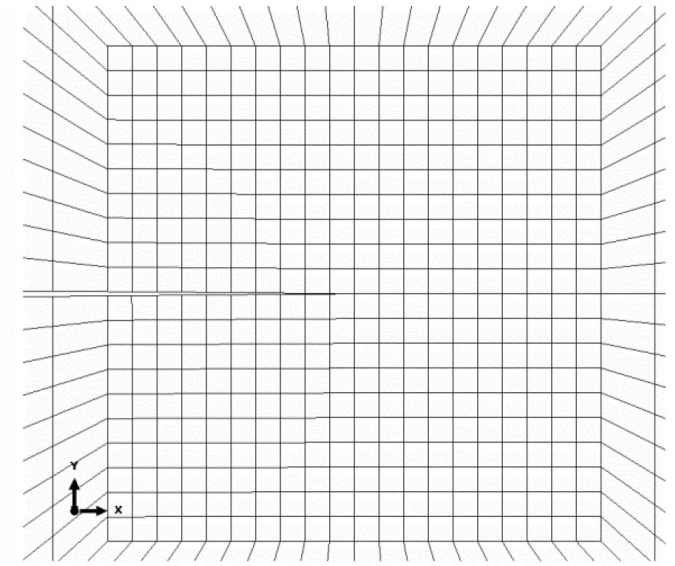

(b)

Figure 6. (a) Finite Element (FE) Mesh for the MBL Analysis and (b) a Zoom of the FE Mesh for the Damage/Fracture Process Window 
Figure 7 illustrates the contour of the damage variable in the process window at the onset of crack propagation predicted by EMTA-NLA/ABAQUS using the damage model for the composite with 3-wt $\%$ MWCNTs ( 0.077 volume fraction). The corresponding value of the stress intensity factor, $K_{\mathrm{I}}$ inducing this damage distribution is $7.78 \mathrm{MPa} \cdot \sqrt{\mathrm{m}}$. The critical value of the damage variable at failure has been identified to be 0.2 for all the MWCNT/3YSZ composites studied in this report. ${ }^{(a)}$ Figure 7 shows that the damage variable has attained the critical value at the crack tip for this loading level, and the stress intensity factor is then identified as the critical stress intensity factor or fracture toughness $\left(K_{\mathrm{I}}=K_{\mathrm{I}}^{\mathrm{c}}=7.78 \mathrm{MPa} \cdot \sqrt{\mathrm{m}}\right)$.

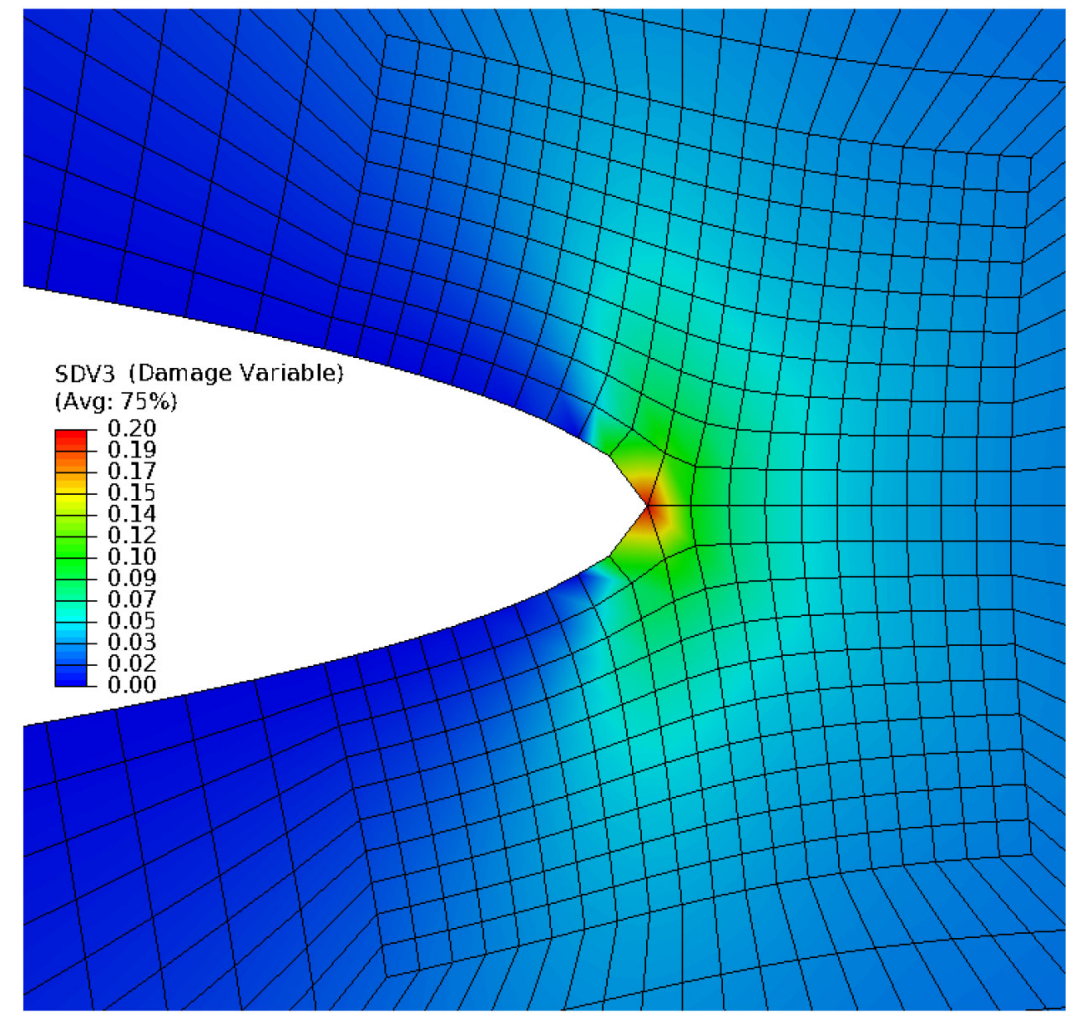

Figure 7. Predicted Damage Distribution at the Onset of Crack Propagation for the $3-w t \%$ MWCNT/3YSZ

Similar EMTA-NLA/ABAQUS MBL analyses using the damage model were performed for all the MWCNT/3YSZ composites with weight fractions from $0.04 \%$ to $1 \%$ (volume fractions from $0.1 \%$ to $23 \%$ ) to predict the fracture toughness of this composite system as a function of the MWCNT content. Predicted fracture toughness results are reported in Figure 8 that shows significant increases in fracture toughness with the increasing MWCNT volume fraction up to about $15 \%$. The predicted evolution appears to saturate for volume fractions higher than $15 \%$. The predicted fracture toughness for MWCNT

(a) Nguyen BN, et al. 2013. "Fracture Toughness Prediction for MWCNT Reinforced Ceramics Using a Modified Boundary Layer Modeling Approach. In preparation. 
volume fractions up to $12.4 \%$ agrees well with Mezaheri et al.'s (2011) experimental results also given in Figure 8.

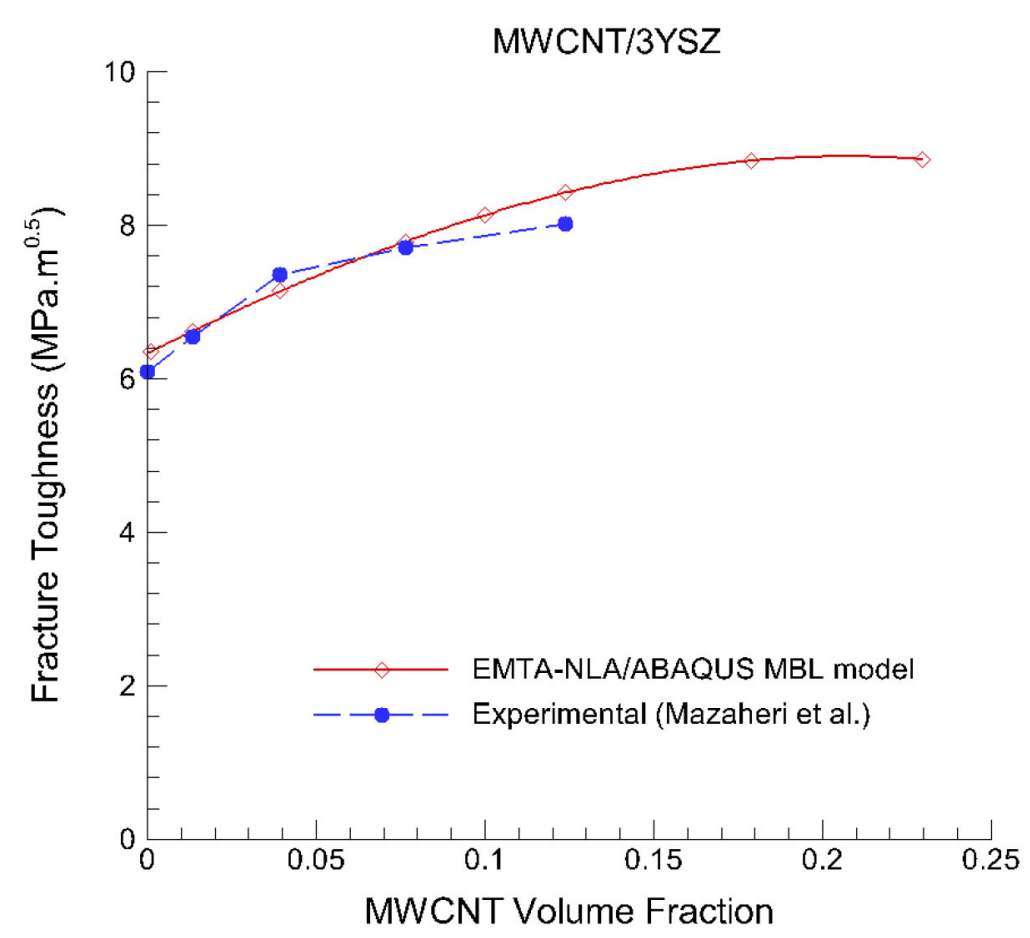

Figure 8. Predicted and Experimental Mode I Fracture Toughness vs. MWCNT Volume Fraction for the MWCNT/3YSZ Composites. The experimental results were determined by Mazaheri et al. (2011) via bending tests of single edge V-notched beam specimens.

Cracks can propagate further in the process window after initiation if the loading is increased. The present MBL analysis was also used to predict the stress intensity factor vs. crack advance (R-curve) as a function of the MWCNT content. Crack propagation was captured by a vanishing element (VE) method used by Nguyen et al. (2006). Once the damage variable has attained the critical value at a given integration point (material point) in a finite element, the VE method reduces the local element stiffness and stresses to zero in a small number of loading steps, and the stresses are redistributed to the adjacent integration points until these points fail to completely fail the element. The failed elements represent an open crack. Figure 9 illustrates the crack propagation in the process window for the $3-\mathrm{wt} \%$

MWCNT/3YSZ composite. The corresponding stress intensity and crack advance (measured from the initial crack tip) are $9.49 \mathrm{MPa} \cdot \sqrt{\mathrm{m}}$ and $0.245 \mathrm{~mm}$, respectively. The failed elements are depicted by the unity value of the failure indicator. 


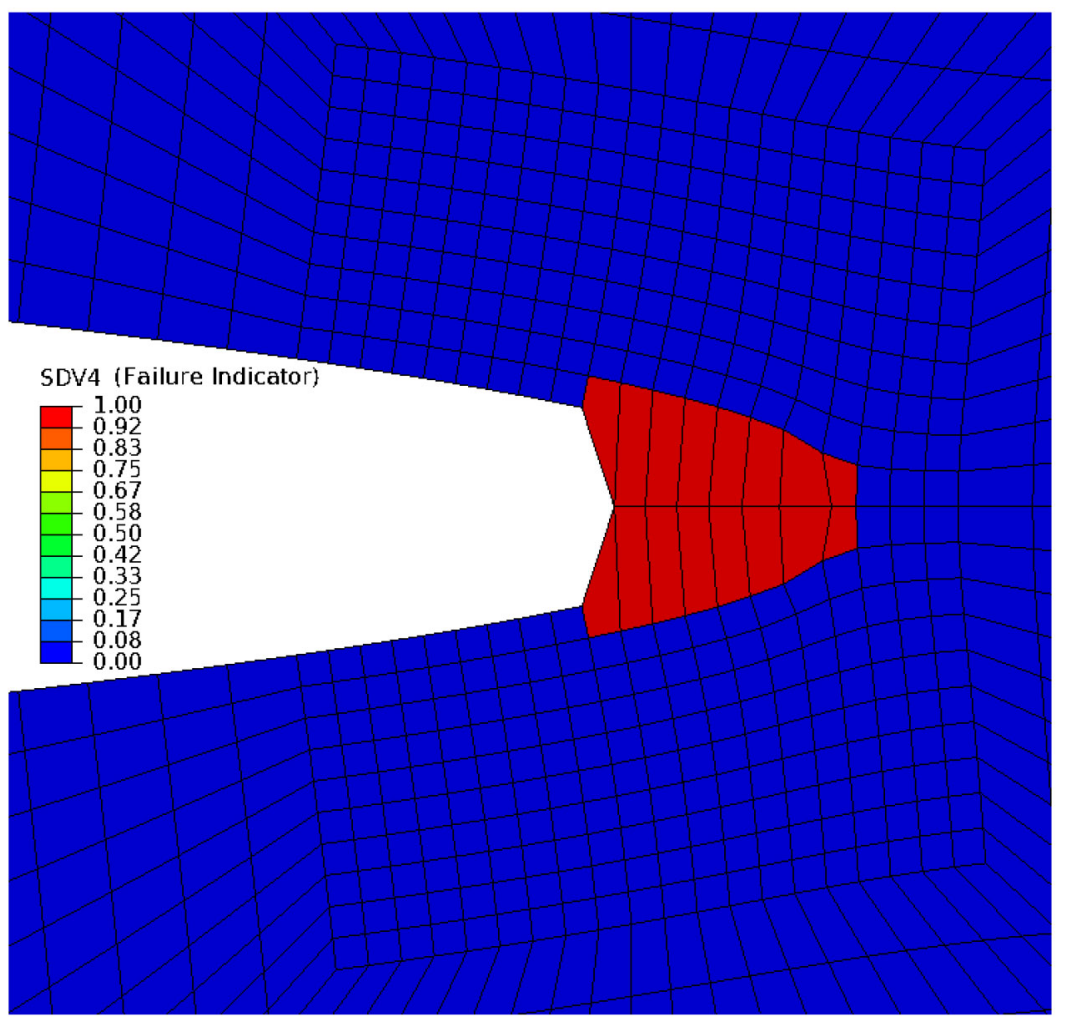

Figure 9. Predicted Crack Propagation for the $3-\mathrm{wt} \% \mathrm{MWCNT} / 3 \mathrm{YSZ}$ at $K_{\mathrm{I}}=K_{\mathrm{I}}^{\mathrm{R}}=9.47 \mathrm{MPa} \cdot \sqrt{\mathrm{m}}$

The R-curves were also predicted by the MBL analysis for the other MWCNT/3YSZ composites with weight fractions from 0.04 to $5 \%$ and the results are reported in Figure 10. For the extent of the crack advance predicted, all the predicted R-curves can be fitted quite well by a power-law of the form:

$$
K_{\mathrm{I}}^{\mathrm{R}}=k c^{\alpha}
$$

where $K_{\mathrm{I}}^{\mathrm{R}}$ is stress intensity factor after the onset of crack propagation and $c$ is the crack advance. $k$ and $\alpha$ are the fitting coefficients. Using Eq. (2), there exists an initial value of $c$ equal to $c_{0}\left(c=c_{0}\right)$ for which the stress intensity factor is equal to the fracture toughness, or $K_{\mathrm{I}}^{\mathrm{R}}=k c_{0}^{\alpha}=K_{\mathrm{I}}^{\mathrm{c}}$. Although the experimental R-curves for the MWCNT/3YSZ composites studied in this report are not known, the predicted power-law trend (Eq. 2) was also experimentally observed in other ceramic composite systems (Krause Jr. 1988; Ramachadran and Shetty 1991; Sarka and Das 2012). Table 1 gives the values of $k$ and $\alpha$ obtained from the fitting of the MBL analysis results (Figure 10) by the power-law (Eq. 2). 


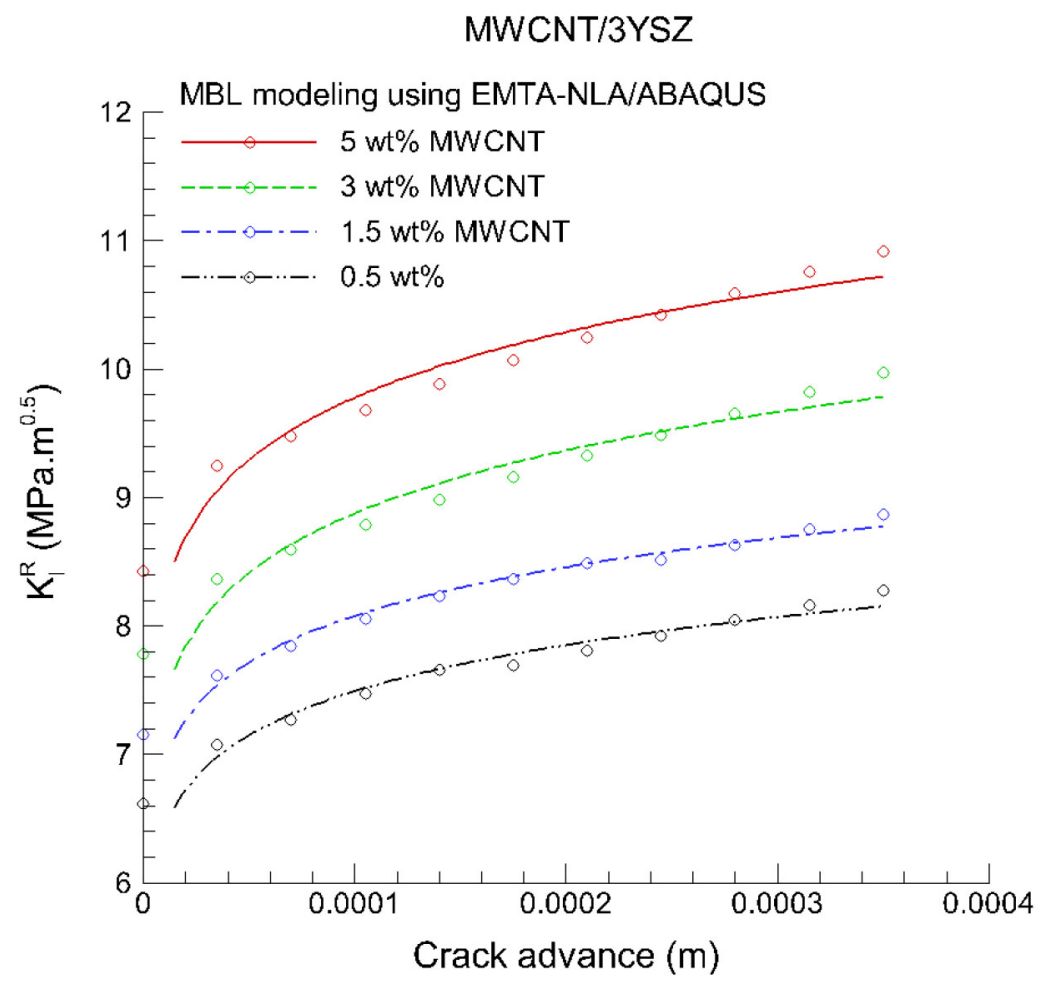

Figure 10. Predicted Stress Intensity Factor vs. Crack Advance for the MWCNT/3YSZ Composites as a Function of MWCNT Content

Table 1. R-curves Power-Law Coefficients Identified for the MWCNT/3YSZ Composites Studied in this Report

\begin{tabular}{ccccc}
\hline MWCNT Content & $\mathbf{0 . 0 5}-\mathbf{w t} \%$ & $\mathbf{1 . 5}-\mathbf{w t} \%$ & $\mathbf{3 - w t} \%$ & $\mathbf{5 - w t \%}$ \\
\hline$c_{0}(\mathrm{~m})$ & $1.5 \mathrm{E}-5$ & $1.5 \mathrm{E}-5$ & $1.5 \mathrm{E}-5$ & $1.5 \mathrm{E}-5$ \\
$k\left(\mathrm{MPa} \cdot \mathrm{m}^{1 / 2} \cdot \mathrm{m}^{-\alpha}\right)$ & 13.93 & 14.82 & 18.1 & 19.22 \\
$\alpha$ & $6.73 \mathrm{E}-2$ & $6.59 \mathrm{E}-2$ & $7.74 \mathrm{E}-2$ & $7.34 \mathrm{E}-2$ \\
\hline
\end{tabular}

\subsection{Conclusions}

This report describes the modeling effort to predict the fracture toughness and crack resistance behavior of MWCNT reinforced ceramic composites. The work aims at providing insight and guidance to processing this class of composite materials to achieve the levels of fracture toughness required for their applications in advanced nuclear reactors. A series of computational steps including computations of the MWCNT composite elastic properties and nonlinear stress/strain responses from damage was necessary and performed prior to the prediction of fracture toughness. The models for elastic properties and damage by matrix cracking were developed and implemented in PNNL's EMTA and EMTA-NLA predictive tools (Nguyen 2010a, b). The damage model associated with a modified boundary layer modeling approach (Nguyen et al. 2006) using ABAQUS has allowed us to efficiently predict the composite toughness and crack resistance behavior. Predictions of elastic properties and fracture 
toughness agree well with Mazaheri et al.'s experimental results (Mazaheri et al. 2011). The modeling results show that homogeneously dispersing low to moderate contents of MWCNTs in a ceramic matrix leads to significant increases in the mechanical properties of the as-formed composite, which has a 3-D MWCNT orientation distribution. However, the increase in strength and toughness saturates at high MWCNT contents and, therefore, it is not possible to achieve the levels of fracture toughness needed for nuclear reactor applications. Currently, we are working on remedying this limitation by making MWCNT mats with very high volume fractions of MWCNTs. The MWCNT mats will be used in a lay-up similar to a laminated composite. Such a microstructure would achieve higher Mode I fracture toughness, as the composite would better sustain the crack opening stresses.

\subsection{References}

Advani SG and CL Tucker III. 1987. "The Use of Tensors to Describe and Predict Fiber Orientation in Short Fiber Composites." Journal of Rheology 31(8):751-784.

Krause Jr. RF. 1988. "Rising Fracture Toughness from the Bending Strength of Indented Alumina Beams." Journal of the American Ceramic Society 71(5):338-343.

Mazaheri M, D Mari, ZR Hesabi, R Schaller and G Fantozzi. 2011. "Multi-walled Carbon

Nanotube/Nanostructured Zirconia Composites: Outstanding Mechanical Properties in a Wide Range of Temperature." Composites Science and Technology 71:939-945.

Nguyen BN. 2010a. EMTA-NLA User's Guide. PNNL-20013, Pacific Northwest National Laboratory, Richland, Washington. Limited Distribution.

Nguyen BN. 2010b. EMTA User's Guide. PNNL-19997, Pacific Northwest National Laboratory, Richland, Washington. Limited Distribution.

Nguyen BN, BJ Koeppel, S Said, MA Khaleel and P Singh. 2006. "Crack Growth in Solid Oxide Fuel Cell Materials: from Discrete to Continuum Damage Modeling." Journal of the American Ceramic Society 89(4):1358-1368.

Nguyen BN, PR Onck and E Van der Giessen. 2000. "Crack-tip Constraint Effects on Creep Fracture." Engineering Fracture Mechanics 65(4):467-490.

Onck PR and E Van der Giessen. 1999. "Growth of an Initial Sharp Crack by Grain Boundary Cavitation." Journal of the Mechanics and Physics of Solids 47:99-139.

Ramachadran N and DK Shetty. 1991. "Rising Crack-Growth-Resistance (R-curve) Behavior of Toughened Alumina and Silicon Nitride." Journal of the American Ceramic Society 74(10):2634-2641.

Sarka S and PK Das. 2012. "Temperature and Load Dependent Mechanical Properties of Pressureless Sintered Carbon Nanotube/Alumina Nanocomposites." Materials Sciences and Engineering A 531:61-69.

Tvergaard V and JW Hutchinson. 1992. "The Relation between Crack Growth Resistance and Fracture Process Parameters in Elastic-Plastic Solids." Journal of the Mechanics and Physics of Solids 40:13771397. 



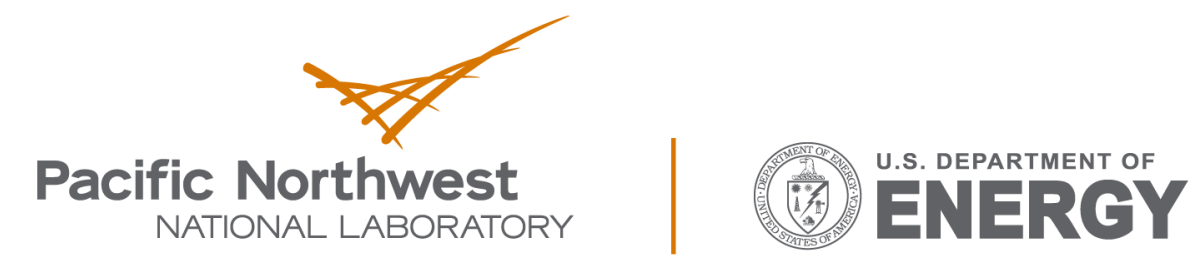

Proudly Operated by Battelle Since 1965

902 Battelle Boulevard

P.O. Box 999

Richland, WA 99352

1-888-375-PNNL (7665)

www.pnnl.gov 